\title{
The indirect effects of auditing taxpayers.*
}

\author{
Marisa Ratto ${ }^{\dagger} \quad$ Richard Thomas ${ }^{\ddagger} \quad$ David Ulph ${ }^{\S}$
}

15 May 2009

\begin{abstract}
In this paper we focus on the effects of investigations on tax compliance. Results from empirical studies suggest that the effects of audits are not only in terms of recovered unpaid tax (direct effects), but there are also indirect effects in terms of future better compliance in the rest of the community. The evidence suggests that such indirect effects tend to outweigh the direct effect. However, current policy decisions of how to allocate investigation resources across different groups of taxpayers generally neglect the indirect effects, generating a potential resource misallocation issue. With the aim to clarify a possible mechanism through which the indirect effects work and hence to inform any policy recommendations, we model tax compliance as a social norm and decompose the total effect of an increase in the audit probability into a direct effect (increased expected fine) and a multiplier effect due to taxpayers' interdependencies.
\end{abstract}

Keywords: tax evasion, social norm, opportunities to evade, optimal audit rule.

JEL: D81, H26, H30, K42.

\footnotetext{
*This paper benefitted from the contributions of participants at the IFS Public Economics Working Group (Warwick, 2004), at the International Conference on Public Economic Theory PET04 (Beijing), at the Royal Economic Society annual conference 2005 (Nottingham), at the Macroeconomic and Policy Implications of Underground Economy and Tax Evasion Conference (Bocconi University 2009), and at seminars at CMPO (Bristol University), Paris 1 Panthéon-Sorbonne and Paris-Dauphine. All remaining errors are ours.

†University Paris-Dauphine (LEDa-SDFi). Corresponding author. maria_luisa.ratto@dauphine.fr. Postal address: University Paris-Dauphine, Place du Maréchal de Lattre de Tassigny 75775 Paris cedex 16 France. Tel.: +33(0)144054947

${ }^{\ddagger}$ HM Revenue \& Customs, London, UK.

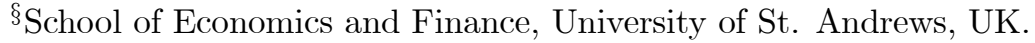




\section{Introduction}

The empirical evidence on the impact of audit rates on taxpayers' compliance suggests an important difference in the magnitude of the direct and indirect effects of investigations - the direct effect being the amount of recovered unpaid taxes through investigations and the indirect effect measuring the increase in tax collections whether or not individuals are investigated. The indirect effects are estimated to substantially outweigh the direct effect. In this paper we are interested in identifying the determinants of the ratio between indirect and direct effects and a possible mechanism through which the indirect effects work. Although the indirect effects have been estimated in empirical studies, the theoretical models on tax evasion do not seem to pay attention to the distinction between the direct and indirect effects of audits. In the standard portfolio models ${ }^{1}$ the tax authority sets the probability of detection, the tax rate and the fine rate independently from the taxpayer's decision. There is no interaction between the tax authority and the representative taxpayer and the tax parameters are fixed, chosen independently from taxpayers' behaviour. Later contributions have analysed, by use of game theoretical models, the interaction between taxpayers and the tax authority. The assumption made in those models is that the choice of the tax parameters depends on the extent of evasion, in that taxpayers' decisions have an impact on the tax revenues raised by the Government ${ }^{2}$. However these models consider the overall response of taxpayers to the audit policy, without distinguishing between direct and indirect effects. We first show the importance of distinguishing between these two types of effects for the optimal allocation of audit resources and then we model a possible mechanism through which the indirect effects may work. The existence of indirect effects stems from taxpayers' interactions, as empirical studies seem to suggest. We model these interactions in terms of a reputational cost of being detected, which depends on the number of honest taxpayers. We show that an increase in the probability of audit has the expected deterrent effect consisting of an increase in the expected fine, but we also identify a multiplier effect of audits which acts through the reputational cost and which could explain the indirect effects estimated in the empirical studies.

The empirical studies we mentioned above are based on non-experimental and nonsurvey data, mainly for the United States. Data consist of time series cross-sectional

\footnotetext{
${ }^{1}$ Allingham and Sandmo (1972), Yitzhaki (1974).

${ }^{2}$ See Reinganum and Wilde (1984),(1991), Graetz et al. (1986) and Cremer et al. (1990), Greenberg
} (1984). 
information from individual tax returns, aggregated at state level. Dubin et al. (1990), using state level data for the period 1977-1986, when there was a sharp decline in the audit rate, estimate the general deterrent or spillover effects of investigations. The authors use the estimated reported tax liability per return and total returns filed per capita to calculate, for each year, the predicted value of total reported tax from individual returns that would have been realised if the audit rate had remained constant at its 1977 level over the period 1977-1986. They estimate that maintaining the audit rate at its 1977 value, by 1986 total reported tax would have increased by 15.6 billion dollars. This value is the indirect effect or spillover effect of investigations. The predicted value for the increase in total assessed liability for 1986 from holding the audit rate to its 1977 value is 18.2 billion dollars. The difference between this figure and the predicted value of total reported tax (15.6 billion dollars) gives a direct revenue effect of 2.6 billion. Hence the ratio between indirect and direct effect is 6:1, i.e. the indirect effects of audits produce six out of every seven dollars of additional revenue. A recent extension of this study by Dubin (2007), includes factors that measure the criminal investigation activity of the IRS and considers the period from 1988 to 2001. Results show a significant magnitude of the general deterrent effect: a simulation on doubling the audit rate suggests a ratio between indirect and direct effects of 15:1. Plumley (1996) presents an econometric analysis on the determinants of voluntary compliance, using a very rich dataset by state and year, from 1982 through 1991. The author uses the percentage of the time that an auditor devotes to audits (Direct Examination Time, DET) and the average DET per audit as instruments for the audit rate. The estimation is on the effect of audits on reported Total Income, Total Offsets and Net Income (Total Income minus Offsets), controlling for tax policy measures ( e.g. filing threshold, allowed exemptions), burden/opportunity variables (e.g. hours needed to complete a tax return, type of income), IRS enforcement measures (audit rate at the start of the period, information return matching program, non-filer notices, refund offsets and criminal tax convictions), IRS responsiveness (telephone assistance, return preparation services) and taxpayers' demographic and economic characteristics. Plumley obtains an estimate for the ratio between indirect effects and direct effects in a similar way than Dubin et al.(1990) and gets a value of 11:1. The only UK study, at our knowledge, is by Mayston and Martin (1998), on the deterrent effects of VAT assurance visits on VAT non-compliance. The authors use cross section data for 48,000 traders across the UK for the year 1996. In their study they calculate the incremental deterrent 
effect, which is the effect on the VAT return declarations that are made by traders who are not the subject of investigation of a one percentage change in investigations. Their results suggest that a one percent increase in the probability of an audit to all traders induces a 0.55 per cent decrease in non-compliance of traders who haven't been investigated.

The fact that taxpayers may be affected by audits even if not directly involved in the assessment seems to be confirmed by surveys and laboratory experiments on taxpayers' attitudes towards non-compliance. Several studies show that individuals' (self-reported) compliance is correlated with their estimate of other individuals' compliance (e.g. Bosco and Mittone, 1997; De Juan et al., 1994; Webley et al., 1988). Torgler (2002) reviews experimental findings on tax compliance, which suggest that there are some interdependencies in individuals' decision of whether or not to evade and their perceptions of other taxpayers' evasion.

In this paper we aim at a better understanding, from a theoretical point of view, of what can drive the indirect effects and of the policy implications that can be drawn. The paper is organised as follows. In the following section, we derive a formalisation of the concepts of direct and indirect effects in a very simple model of optimal allocation of audit resources among different groups of taxpayers. In section 3 we model social interactions among taxpayers in terms of a reputational cost of being investigated and consider the impact of a rise in the audit rate on aggregate evasion. We show that the normal deterrent effect (as in the standard portfolio approach) is reinforced by the presence of a social norm.

\section{The indirect and direct effects of investigations}

In this section we model the optimal allocation of investigation resources across different categories of taxpayers, when the enforcement agency has a fixed budget to carry out investigations. To reflect actual behaviour from the enforcement agency, the model assumes that the enforcement agency's objective function is to minimise the tax gap, defined as the amount of evasion which is not recovered through investigations ${ }^{3}$.

Let $N_{k}$ be the number of taxpayers of type $k$, the type being defined for exemple by the type of activity undertaken (i.e. individual taxpayers vs businesses) and $E_{k}$ the average amount of evasion carried out by taxpayers of that type. The probability of

\footnotetext{
${ }^{3}$ This is the actual target (Public Service Agreement target) for HM Revenue and Customs.
} 
being audited for taxpayers of type $k$ is $p_{k}$. The total number of investigations carried out on taxpayers of type $k$ is $I_{k}=p_{k} N_{k}$. We define the ratio of the average amount recovered per investigation of taxpayers of type $k$ to the average amount of evasion per taxpayer of type $k$ as $\theta_{k}^{4}$. The cost of carrying out such an investigation is $c_{k}$. We assume taxpayers differ in the frequency with which they are investigated and in each group their behaviour depends solely on the frequency of audit with which the group is targeted, via the function $E_{k}\left(p_{k}\right)$. There are $m$ different types of taxpayer. We measure the responsiveness of taxpayers of type $k$ to the audit rule in terms of the elasticity of evasion: $\varepsilon_{k}=-\frac{d E_{k}}{d p_{k}} \frac{p_{k}}{E_{k}}$.

We should note few points before proceeding.

- In the behavioural relationship adopted above we are not assuming that taxpayers necessarily correctly perceive the true frequency with which their group is inspected, just that there is some relationship between the actual frequency of inspection, the perceived frequency of investigation and behaviour. We are not modelling these more fundamental relationships, but we just adopt a reduced form that relates behaviour ultimately to the actual frequency of inspection. So the elasticity defined above confounds two elasticities: the sensitivity of evasion behaviour to the perceived frequency of inspection and the sensitivity of the perceived probability of inspection to the actual frequency of inspection. It is important to distinguish between the two elasticities as they measure different aspects of the individual response to audits. They may also take very different values: an individual may be very sensitive to the perceived odds of being investigated, but the actual probability and perceived probability may be matched very poorly. Or the opposite might occur. Hence the weak response to investigations which emerges from some of the empirical studies using individual level data, could be compatible with a high sensitivity of

\footnotetext{
${ }^{4}$ There are two factors bearing on the value of $\theta$ for any given group. First, for a variety of reasons the tax authority would not necessarily expect to recover in any particular investigation the full amount of tax that is actually evaded, which would suggest $\theta<1$. On the other hand there may be a great deal of targeting of resources within group $k$ so that investigations are devoted to the high end of the spectrum, in which case we could have $\theta>1$. Also, if the enforcement agency is carrying out an investigation over multiple years, it might well be the case that $\theta>1$. Which value of $\theta$ will apply in any circumstance depends on the heterogeneity of the group and the extent to which investigations are targeted on high yield or affect a long period of time. If the group is pretty homogeneous or if taxpayers are selected more or less at random, we would expect $\theta<1$.
} 
evasion behaviour to perceived probability if perceive probabilities do not adjust precisely to a change in actual probabilities. Alternatively, a low response to audits could be due to a low sensitivity to perceived probability, even if the match between actual and perceived probability is perfect.

- It is also important to recognise that the elasticity defined above measures the average behavioural response of taxpayers in the same group. It is a population elasticity rather than an individual elasticity. This has two implications. First, this allows for considerable heterogeneity of individual sensitivity within the group. Secondly, this is consistent with the possibility that taxpayer behaviour might not be based on a purely individualistic calculus but might be affected by the proportion of taxpayers within the group who are compliant, thus reflecting some kind of social norms at work. The advantage of the very reduced form specification of individual behaviour that we have employed is that it is consistent with a wide range of deeper structural models.

- In principal behaviour will depend on many factors other than the probability of investigation. It will also depend on: the likelihood of the investigations being effective - and hence on $\theta_{k}$; the likelihood that, if effective, a penalty will be imposed. Since here we are mainly interested in the allocation of investigation resources we do not consider these other behavioural factors, but recognise their presence through the fact that the elasticity can vary across groups.

- On the other hand we are not allowing for the possibility that the behaviour of taxpayers of type $k$ depends on the frequency with which other groups are investigated - as might be the case if people's perceived probability of being investigated depends on what they hear from taxpayers in other groups about their experience.

- In this setting we focus purely on the number of investigations carried out. There is also an issue of the quality of investigations. What we might expect is that there is a quality continuum to investigations, and that higher quality investigations (i) require more resources $C$; (ii) recover a higher fraction of evasion $\theta$, and, possibly, (iii) have a bigger impact on taxpayer behaviour, $\varepsilon$. It would be interesting to investigate what could be said about the optimal quality of investigations balancing off all these considerations. However, for the purposes of this paper, the assumption 
we make is that the quality of investigations - and hence $C, \theta, \varepsilon$ - is fixed, possibly because managers have already chosen the optimal quality. We are not ignoring quality and assuming that it is the cheapest, lowest cost type of investigation that should be pursued. So, once again, the reduced form model employed here is consistent with a deeper structural account of there being a spectrum of investigation technologies.

The total expected amount of evasion by taxpayers in group $k$ is $N_{k} E_{k}$, while, if they are inspected with frequency $p_{k}$, then the total expected compliance yield from investigations will be $N_{k} p_{k} \theta_{k} E_{k}$. So the total tax gap from group $k$ will be:

$$
G_{k}=N_{k} E_{k}\left\{1-p_{k} \theta_{k}\right\}
$$

The cost of investigating taxpayers in group $k$ is $c_{k} p_{k} N_{k}$. The objective of the enforcement agency is to select the frequency of an audit for each group of taxpayers in order to minimise the tax gap, subject to the constraint that only a limited amount of resources $(C)$ can be devoted to investigations:

$$
\min \sum_{\substack{k=1 \\ p_{k}}}^{m}\left\{N_{k} E_{k}\left[1-p_{k} \theta_{k}\right]\right\} \quad \text { s.t. } \sum_{k=1}^{m} c_{k} p_{k} N_{k} \leq C
$$

The first order condition for an interior solution is:

$$
N_{k}\left\{\frac{d E_{k}}{d p_{k}}\left[1-p_{k} \theta_{k}\right]-\theta_{k} E_{k}\right\}-\lambda N_{k} c_{k}=0
$$

where $\lambda$ is the Lagrange multiplier on the resource constraint, representing the marginal reduction in the tax gap that could be brought about by an additional unit of resources for investigations.

With a bit of re-arranging we can re-write (3) as:

$$
\frac{E_{k} \theta_{k}-\varepsilon_{k} E_{k} \theta_{k}+\frac{\varepsilon_{k} E_{k}}{p_{k}}}{c_{k}}=\lambda
$$

Equation (4) characterises the optimal allocation of investigation resources. The expression on the left hand side represents the ratio of the marginal reduction in the payment/tax gap brought about by a unit increase in the frequency of inspections for group $k$, to the marginal cost of a unit increase in the frequency of inspections for group $k$.

An optimal allocation of resources implies that the marginal benefit:cost ratio should be the same across groups of taxpayers. This common marginal benefit:cost ratio will 
measure the marginal benefit of increasing resources available for investigation by 1 unit. Equation (4) also tells us that the optimal allocation of resources is independent of the size of the population of taxpayers in group $k$. It is the average yield for taxpayers in group $k$ that matters not total yield.

We are interested in the expression for the marginal reduction in the payment gap (MRPG), the numerator of equation (4). We can write this as:

$$
M R P G_{k}=E_{k} \theta_{k}-\varepsilon_{k} E_{k} \theta_{k}+\frac{\varepsilon_{k} E_{k}}{p_{k}}
$$

Equation (5) allows us to explain the direct and indirect effects of investigations. The expression shows that there are three effects to be considered.

The first term of equation (5) represents the immediate yield brought in from an extra investigation. If one extra investigation is carried out, since each investigation is expected to yield $E_{k} \theta_{k}$ on average, then this is what the enforcement agency expects to get from the extra investigation.

The second and third terms of equation (5) represent the behavioural response of all taxpayers to an increase in the frequency of audit. A reduction in the average amount of evasion by all taxpayers in group $k$, means that all investigations (and not just the additional one) will find that the amount brought in from each investigation is now a bit lower. This effect is measured by the term $\varepsilon_{k} E_{k} \theta_{k}$. However a reduction in the average amount of evasion also means that the tax gap is reduced. The term $\frac{\varepsilon_{k} E_{k}}{p_{k}}$ captures the (absolute) reduction in the average amount of evasion brought about by a unit increase in the frequency of investigations. It is inversely proportional to the frequency with which the group is investigated. The smaller the number of investigations that the enforcement agency currently carries out, the greater will be the percentage increase that one additional investigation will represent. This is the compliance effect of an increase on investigations ${ }^{5}$. So which of these are the direct effect and which the indirect effect? There are two possibilities. We can interpret the direct effect as the effect on yield, and hence consider the first two terms in equation (5) as the direct effect, or, and we believe this is more appropriate to reflect what we mean by direct and indirect effects, we can consider the

\footnotetext{
${ }^{5}$ We should note that here we are ignoring any timing issue, which is likely to affect the direct and the effect in a different way, in that the behavioural response to an increase in the frequency of investigations is going to be observed later than the direct effect on the discovered evasion. For simplicity here we only consider one period, thereby modelling a steady state.
} 
direct effect as the immediate yield from investigations and the indirect effect as the behavioural impact of the actions of the tax authority. In this case the first term of equation (5) represents the direct effect and the second and third terms the indirect effect. The most important point is that, whatever the definition one adopts, there is absolutely no reason to think that this ratio is constant across fiscal areas. Indeed there is absolutely no reason to think that this ratio is going to be constant across different taxpayer groups within a fiscal area. For even if we thought that the behavioural elasticity, $\varepsilon$, was relatively constant across groups, the ratio depends on an operational/resource decision - how intensively to investigate taxpayers, $p$, and on the operational effectiveness of fraud investigations, $\theta$, both of which will certainly vary both across and within fiscal areas.

It is also clear that if the allocation of investigation resources is merely based on a direct yield:cost ratio from the different audits ${ }^{6}$, the resulting decision will be suboptimal as only part of the marginal benefit of an increase in the audit rate is taken into account. One problem of focusing on direct yield is that the decision may be in favour of allocating more resources to increase short-term yields at the expense of reducing the deterrent effect in the short/long run.

Given the relevance of the indirect effects in determining the optimal allocation of audit resources and their considerable magnitude as suggested by the empirical studies, it is important to understand how these indirect effects work. There may be different mechanisms through which audits affect the behaviour of individuals who are not personally involved in the investigation. In the next section we explore one possibility: the presence of social interactions among taxpayers.

\section{Taxpayers' response to an increase in the frequency of audits in the presence of a social psychic cost of being investigated}

The elasticity of evasion we considered in the last section is a population elasticity. As already mentioned, this concept may capture the role of social interactions across taxpay-

\footnotetext{
${ }^{6}$ Actual targets for the different interventions to monitor compliance are set on such a ratio, at least in the UK and USA, as this is currently the only available measure of the effects of an audit.
} 
ers. The existence of a social dimension in the choice of whether or not to evade has been suggested by the results of several empirical studies. Frey and Torgler (2004), using data from the European Values Survey, perform a multivariate analysis across 30 countries and provide evidence on the relevance of conditional cooperation for tax morale. They show a positive correlation between people's tax morale (measured by a question whether cheating on tax is justified if one has the chance) and people's perceptions of how many others cheat on taxes. This is confirmed by Gächter (2006), who presents evidence from four laboratory experiments suggesting that people are less likely to cheat on their taxes or to commit benefit fraud if they have the impression that others behave honestly. The underlying idea of these studies is that taxpayers are intrinsically motivated to comply with the tax system by feelings of guilt or shame and are deterred from cheating by informal sanctions together with formal sanctions. According to some authors (Frey, 2003, Frey and Jegen, 2001) the presence of implicit incentives or moral rules to comply may clash with the monitoring and punishing activity of the tax authority. The argument made is that monitoring may crowd out intrinsic motivation to comply. Although surveys and laboratory experiments converge to the result of the relevance of morals on taxpayers' decision, the results from other empirical studies cast some doubts on how morals actually translate into taxpayers' behaviour. For example Blumenthal et al (2001) conduct a field experiment on the effects of normative appeals on tax compliance, but do not find any compelling effects of morals, their results suggesting instead the role of opportunities and costs of evasion in determining tax compliance. This seems to be confirmed by other studies using individual level data from tax returns ${ }^{7}$.

Recent developments of the standard theoretical model of tax evasion have considered the interdependencies of taxpayers' decisions. In these models individuals are assumed to attach a moral content to tax compliance and to suffer a psychic cost when opting for non-compliance. Gordon (1989) considers the case of a social stigma attached to the act of evading taxes, which is suffered irrespective of being detected: making a truthful declaration to the tax authority has a moral connotation and the higher the number of other honest taxpayers, the higher the social stigma of evading taxes. Myles and Naylor (1996) capture the influence of social interactions in the taxpayers' decision whether or not to evade in the framework of the social custom and conformity approach. In their model a social custom utility is derived when taxes are paid honestly. Individuals also get

\footnotetext{
${ }^{7}$ See Slemrod et al. (2001), Crane and Nourzad (1993) and Erard and Ho(2001)
} 
an extra utility from conforming with the standard pattern of social behaviour. Hence the utility from non-evasion includes two extra arguments that were neglected in the standard portfolio model: a fixed gain from following the social custom and an extra gain from conforming to the other honest taxpayers, which depends on the number of honest taxpayers. Like in Gordon (1989), Myles and Naylor assume that there is a moral dimension in the act of behaving honestly. Individuals get non-monetary gains from a truthful declaration (or equivalently, tax evasion causes a non-pecuniary cost). In our model of social interactions we adopt a different approach than Gordon (1989) and Myles and Naylor (1996). In line with the rather uncompelling results of empirical studies on the role of morals on tax evasion, we adopt a less strong moral connotation attached to tax compliance: individuals suffer an extra psychic cost for evading only in case of detection. The loss of reputation is not linked to the act of evading, but rather to the fact of being caught. There is not necessary any personal conviction that paying taxes honestly is morally right, i.e. there is no personal moral cost of evading. The psychic cost is rather due to the fact of being discovered evading, it is a reputational cost rather than a personal moral cost. In line with the empirical evidence we mentioned above, suggesting that people's perceptions of how many others individuals cheat on taxes are important determinants for individual behaviour, we assume that this psychic cost is decreasing with the perceived number of cheaters in the community. Note that, in this case, we can rule out any crowding effects of intrinsic motivation to comply on the monitoring activity of the tax authority, as the non-monetary cost of evasion is triggered by detection and the individual is not intrinsically motivated to behave honestly ${ }^{8}$.

The main aim of our model is to analyse how taxpayers' response to an increase in the probability of an audit is affected by the presence of social interactions. The previous models on social interactions did not consider this issue, as their main focus was to explain why taxpayers tend to be more honest than expected by the standard portfolio model. We compare two settings: one in which tax compliance is simply an opportunistic behaviour, based on purely monetary considerations, which is the same approach as the standard portfolio model. We then consider the case where there is a reputational loss of being investigated, the magnitude of which depends on the number of other honest taxpayers. In the analysis that follows we make the following assumptions:

\footnotetext{
${ }^{8}$ This would be the case if the psychic cost were a personal cost, born irrespective of being audited.
} 
- Risk neutrality. We consider the taxpayer decision as a two-step decision: the taxpayer first decides whether or not to evade, by comparing the utility of nonevasion with the expected utility of evasion and then chooses the optimal amount of evasion. We focus on the decision whether or not to engage in tax evasion, for which our assumption of risk neutrality is not relevant. In fact the degree of risk aversion does not affect the decision whether or not to evade: tax evasion will be chosen whenever the probability of being detected is below a certain threshold, determined by the value of the fine and tax rate ${ }^{9}$. The degree of risk aversion affects instead the decision of how much to evade. Hence our results are not qualitatively affected by the assumption of risk aversion, which we make to keep notation simple and in order to focus on the effects of social interactions.

- The probability of an audit is fixed and audits are 100\% successful, as in the standard portfolio model: once an individual is investigated, tax evasion is fully detected.

- We keep the assumptions we made in section 2 and do not model taxpayers' perceptions of being audited: we just adopt a reduced form that relates individual behaviour to the actual frequency of investigations. Moreover, in terms of the model in section 2, we examine the behaviour of individuals belonging to the same group $k$ and assume that only the probability of being investigated in group $k\left(p_{k}\right)$ matters, i.e. audit rates do not have any spillover effects across groups.

\subsection{Selfish calculus.}

We first consider the setting of the standard portfolio model, where the taxpayer decides whether or not to evade on the basis of a selfish and purely monetary calculus.

\footnotetext{
${ }^{9}$ This condition ensures that the expected utility from evasion is greater than the utility from non evasion. In an income-state dependent diagram this condition implies that the slope of the indifference curve at a point along the 45 degree line, $\frac{-(1-p)}{p}$, is more negative than the slope of the budget constraint $-\left(\frac{t-f}{t}\right)$ as in Allingham and Sandmo (1972) or $(1-f)$ as in Yitzhaki (1973) - so that the point of tangency between the indifference curve and the budget constraint must lie below the 45 degree line, thus implying a positive amount of evasion.
} 


\subsubsection{Individual behaviour}

We first focus our analysis at the individual level. We define the utility from non evading for an individual with income normalised to land facing a tax rate $t$ as:

$$
U^{N E}=(1-t)
$$

Let $e, 0 \leq e \leq 1$, be the individual's opportunity to evade, i.e. the proportion of income that can potentially be hidden and $\widetilde{e}, 0 \leq \widetilde{e} \leq e$, the actual proportion of income evaded. An individual is investigated with probability $p, 0<p<1$, and in case of evasion he/she will need to pay back the taxes due and a monetary fine $F>0$ on the amount of evaded income, $\widetilde{e}$ (as in Allingham and Sandmo, 1972). Hence the utility from evading is:

$$
U^{E}=p[(1-t)-F \widetilde{e}]+(1-p)[(1-\widetilde{e})(1-t)+\widetilde{e}]=(1-t)+\widetilde{e}[t(1-p)-p F]
$$

An individual is willing to evade if $U^{E}>U^{N E}$. Hence tax evasion will occur whenever if $\widetilde{e}[t(1-p)-p F]>0$. If $t(1-p)-p F>0$ the expected financial gain from evading one extra unit of income is positive and the taxpayer will always evade to the maximum amount, so $\widetilde{e}=e^{10}$. The expression $t(1-p)-p F$ is decreasing in $F$, so that there will be an $\bar{F}$ such that $t(1-p)-p \bar{F}=0$. For this particular value of the fine rate the individual will be indifferent between evasion and non evasion. Hence, $\bar{F}=\frac{t(1-p)}{p}$ defines the critical value above which an individual will opt for full compliance, as, above $\bar{F}, t(1-p)-p \bar{F}<0$ and tax evasion is not profitable on the margin.

If taxpayers face the same tax parameters there will be a unique value of $\bar{F}$ above which everybody will evade, even if their income differs. Note, also, that the only way to affect the decision whether or not to evade is to vary $\bar{F}$. In this case, in fact, opportunities to evade are not affected by any of the tax parameters. Above $\bar{F}$ tax evasion will occur whenever $e>0^{11}$.

\footnotetext{
${ }^{10}$ We should note that here both the probability of detection $p$ and the fine rate $F$ are fixed and do not depend on the amount of evasion. In reality both the frequency of an audit and the fine rate are positively related to the amount of concealed income. This may imply that tax evaders do not evade to the maximum extent of their possibilities.

${ }^{11}$ Whenever $e>0, U^{E}>U^{N E}$, and an individual will engage in tax evasion.
} 


\subsection{Non-pecuniary loss for being investigated.}

We now consider the case where the act of being caught evading may imply some loss in reputation, or some psychic cost for feeling guilty or ashamed. This non-pecuniary cost is very likely to differ across individuals: the loss of reputation for being caught evading may be higher for a corporation than for an individual or for a person with a high public profile. Similarly, the feeling of guilt or shame may be quite personal and differ across individuals, regardless of their occupation. We make the assumption that this loss in reputation or psychic cost depends on the number of people in the community who evade. The idea being that the larger the number of evaders in a community the lower the psychic cost of being caught. So, the total loss in case of detection is ${ }^{12}$ :

$$
f_{i}=F+\lambda_{i} C(1-\mu)
$$

where $F$ is the monetary fine rate, as decided by the fiscal authority, $\lambda_{i}>0$ is the importance attached by individual $i$ to the non-pecuniary loss of being caught and $C(1-\mu)$ is the non-pecuniary cost of being caught, with $\mu$ being the proportion of evaders in the community. We assume $C^{\prime}(\cdot)>0$, to reflect the fact that the larger the proportion of honest taxpayers in the community, the larger the psychic cost of being caught. In our model, the interdependency between taxpayers is captured by the social stigma of being investigated. If there is a sufficiently high proportion of honest taxpayers in the community, the expected loss in reputation can be so substantial to deter tax evasion even if the expected monetary gain is positive. As we shall see, tax compliance may become in this case a self-enforcing behaviour, i.e. a social norm.

\subsubsection{Individual behaviour}

For a single individual $i$, the utility from non evasion is

$$
U_{i}^{N E}=(1-t)
$$

and the utility from evasion is:

$$
U_{i}^{E}=p\left[(1-t)-f_{i} \widetilde{e}_{i}\right]+(1-p)\left[\left(1-\widetilde{e}_{i}\right)(1-t)+\widetilde{e}_{i}\right]=(1-t)+\widetilde{e}_{i}\left[t(1-p)-p f_{i}\right]
$$

\footnotetext{
${ }^{12}$ Note that this non pecuniary cost is suffered in case of detection only, to reflect feelings of guilt or shame of prosecution with regard to the other members of the community and it is not a private cost incurred regardless of being investigated.
} 


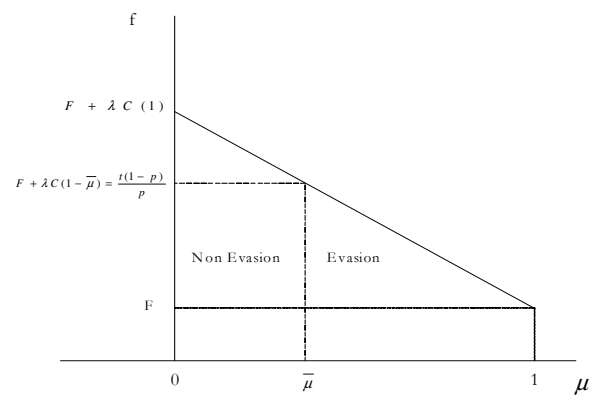

Figure 1: Tax evasion decision when there is a psychic cost of being caught

The net expected total gain from evading one extra unit of income includes monetary and non-monetary considerations and becomes $t(1-p)-p\left(F+\lambda_{i} C(1-\mu)\right)$, which is increasing in $\mu$. As in the purely monetary fine case we considered above, there will be a threshold level $\overline{f_{i}}$ such that $t(1-p)-p\left(\overline{f_{i}}\right)=0$, above which an individual will opt for full compliance. We shall assume that from a monetary point of view, evasion is always worth it, i.e. $F<\frac{t(1-p)}{p}$ and that there is always an opportunity to evade, i.e. $\widetilde{e_{i}}>0$, so that an individual would evade the proportion of income equal to his/her opportunity of evasion. Given that the expected total gain from evading one extra unit of income is increasing in $\mu$, there will be a unique $\bar{\mu}$ such that the net expected marginal gain of tax evasion is zero, i.e. $t(1-p)-p\left(F+\lambda_{i} C(1-\bar{\mu})\right)=0$. For given tax parameters and a given value attached to the importance of the reputational loss or psychic cost of being audited, values of $\mu>\bar{\mu}$ will induce tax evasion, as for $\mu>\bar{\mu}$ the net expected marginal gain of tax evasion becomes positive.

We first notice that the threshold level $\bar{f}$ will vary across individuals depending on $\lambda_{i}$. This implies that it will be possible to observe some individuals opting for evasion and others being fully compliant even if they face the same tax parameters. A mixed equilibrium of evaders and non-evaders will be possible. In figure 1 we represent the individual's decision whether or not to evade.

We represent the total fine $f=F+\lambda_{i} C(1-\mu)$ on the vertical axis, as a function of the proportion of evaders in the community, which is represented on the horizontal axis. The total fine is decreasing in the proportion of evaders. There will exist a $\bar{\mu}$ such that $f=\bar{f}$ and hence such $t(1-p)-p\left(F+\lambda_{i} C(1-\mu)\right)=0$. At this point the individual will be indifferent between cheating and honestly declare his/her taxes. Above $\bar{\mu}$, the total expected cost of being detected will be lower than the expected gain of evading and 


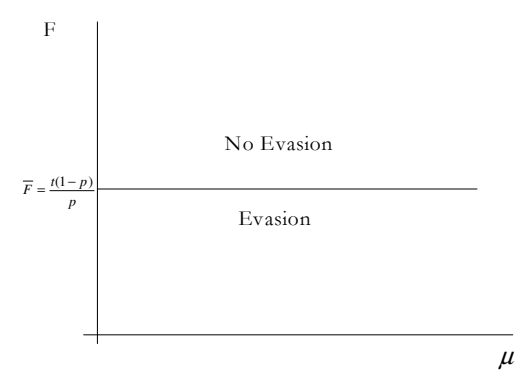

Figure 2: Tax evasion decision with a pure monetary cost of being detected.

the individual will be willing to evade. Hence $\bar{\mu}$ represents the critical proportion of tax evaders above which an individual would consider to evade.

If we compare this context to the situation of a purely monetary fine, we can see that, in the presence of a psychic cost, the tax authority has more margin to combat tax evasion. In the case of a pure monetary fine, tax evasion could be discouraged only by altering the tax parameters and setting the fine rate above $\bar{F}=\frac{t(1-p)}{p}$, as illustrated in figure 2. When there is a psychic cost of being apprehended, the government could implement policies to affect the psychic cost, for example by implementing educational programs to enhance the importance of the reputational loss $\left(\lambda_{i}\right)$. The tax authority can attain the same extent of deterrence by setting a lower monetary fine, as the fine and the psychic cost are substitutes in deterring tax evasion.

\subsubsection{The community}

In our model opportunities to evade are exogenous, in that they are not affected by the tax parameters and the psychic cost. Given that we assume $\widetilde{e_{i}}>0$, opportunities to evade only affect the total amount of evasion and not the number of evaders ${ }^{13}$. In what follows we concentrate on the total number of evaders rather than on total evasion, so that we can simplify notation. Our results are not affected by the distribution of opportunities to evade across the population of taxpayers. We assume taxpayers differ in the importance attached to the non-pecuniary fine for being audited $\lambda_{i}$. The density function for $\lambda$ is $h(\lambda)$ and we assume it is continuous and that the support of $h(\lambda)$ is $[0,+\infty[$. As we have already defined, $\bar{f}$ is the threshold level of the fine below which tax evasion is profitable. For given tax parameters and a given critical proportion of evaders, some individuals will have $\lambda_{i}$ such that they will be above $\bar{f}$ and some will be below $\bar{f}$. The distribution of

\footnotetext{
${ }^{13}$ In fact, if $\widetilde{e_{i}}>0$, the entry condition for tax evasion is not affected by opportunities to evade.
} 
$h(\lambda)$ will determine how many individuals evade. We denote the value of $\lambda_{i}$ such that $f=\bar{f}$ as $\bar{\lambda}=\frac{t(1-p)-p F}{p C(1-\bar{\mu})}$.

Let

$$
m(\mu ; F, p, t)=\int_{0}^{\bar{\lambda}(t, p, F, \bar{\mu})} h(\lambda) d \lambda=H(\bar{\lambda}(\cdot))
$$

be the proportion of taxpayers in the community that are willing to evade. Notice that

$$
\frac{\partial m}{\partial \mu}=\left[\frac{\partial \bar{\lambda}}{\partial \mu} h(\bar{\lambda})\right] \geq 0
$$

since $\frac{\partial \bar{\lambda}}{\partial \mu}=-[t(1-p)-p F][p C(1-\mu)]^{-2}[p C \prime(1-\mu)(-1)]>0$. Notice that

$$
m(1 ; F, p, t)=\int_{0}^{\infty} h(\lambda) d \lambda
$$

which is independent of $\lambda$, though, for $\mu<1$ an increase in $\lambda$ will make the entry condition for evasion more restrictive, hence will lower $m$. The equilibrium value of $\mu, \widehat{\mu}$, is given by

$$
\widehat{\mu}=m(\widehat{\mu} ; F, p, t)=H(\bar{\lambda}(\widehat{\mu}))
$$

It occurs when the distribution of the importance attached to the psychic cost is such that, if every individual faces the same proportion of evaders $\widehat{\mu}$, the actual proportion of evaders in the whole economy, $m(\widehat{\mu} ; F, p, t)$, will be just $\widehat{\mu}$, i.e. $\widehat{\mu}$ is a fixed point for $m(\widehat{\mu} ; \cdot)$. In other words, an equilibrium in the whole community occurs when, given the actual proportion of tax evaders in the population, no one has an incentive to switch from evasion to non-evasion, or vice versa.

We now check what types of equilibria there might exist.

\section{a) Zero evasion equilibrium}

It is easily seen that an equilibrium with zero-evasion will not be possible as:

if $\widehat{\mu}=0$, then $\bar{\lambda}(0)=\frac{t(1-p)-p F}{p C(1)}>0$. Hence $H(\bar{\lambda}(0))>0$. This implies that $\widehat{\mu}=0$ cannot be an equilibrium.

b) Full evasion equilibrium

if $\widehat{\mu}=1$, then $\bar{\lambda}(1)=\frac{t(1-p)-p F}{p C(0)}$. Unless $C(0)=0, \bar{\lambda}(1) \neq+\infty$. Hence $H(\bar{\lambda}(1))<1$. This implies that $\widehat{\mu}=1$ cannot be an equilibrium, unless $C(0)=0$. 


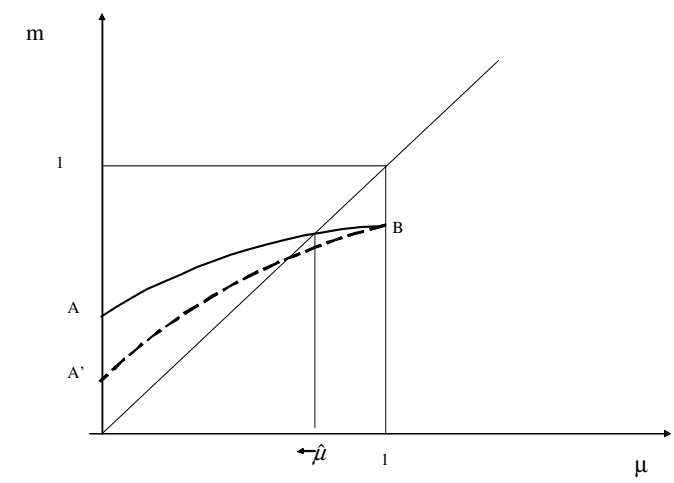

Figure 3: An interior equilibrium of tax evaders. Effect of an increase in the importance attached to the reputational cost.

c) Interior equilibria

As $m(\mu ; F, p, t)$ is a continuous function of $\mu$, the existence of at least one interior equilibrium is guaranteed. A sufficient condition for the interior equilibrium to be unique is that $\frac{\partial m}{\partial \mu}$ is monotonic.

Note that:

$$
\frac{\partial^{2} m}{\partial \mu^{2}} \approx h \prime(\bar{\lambda}(\mu)) \frac{C \prime^{2} K^{2}}{C^{4}}+h(\bar{\lambda}(\mu)) \frac{2 C C^{2}-C^{\prime \prime} C^{2}}{C^{4}} K
$$

with $C \prime=C \prime(1-\mu)$ and $K=\frac{t(1-p)-p F}{p}$.

All we can say about the sign of equation 14 is that if $C$ " $<0$, and $h \prime(\bar{\lambda}(\mu)) \geqq 0$ (or not too negative), then $\frac{\partial^{2} m}{\partial \mu^{2}}>0$. The same is valid if $C^{\prime \prime}>0$, but not too much. We obtain $\frac{\partial^{2} m}{\partial \mu^{2}} \leq 0$ if $C^{\prime \prime} \geqq 0$ and $h \prime(\bar{\lambda}(\mu)) \leq 0$ and $K$ is big enough

In conclusion, the existence of multiple equilibria depends on the shape of the psychic cost function $\left(C^{\prime}, C^{\prime \prime}\right)$ and on the distribution of the importance attached to the psychological cost of being audited $(H(\bar{\lambda}), h(\bar{\lambda}(\mu)), h \prime(\bar{\lambda}(\mu)))$.

In what follows we shall assume the existence of a unique interior equilibrium and consider the comparative statics for a change in the audit rate. We make the assumption that $C(0) \neq 0$ and that $C " \geqq 0$ and $h(\bar{\lambda}(\mu)) \leq 0$ and $K$ is big enough so that $\frac{\partial^{2} m}{\partial \mu^{2}} \leq 0$. Results are however valid for any locally stable interior equilibrium. The equilibrium is represented in figure 3 for $\frac{\partial^{2} m}{\partial \widehat{\mu}^{2}} \leq 0$.

The function $m(\mu)$ is represented by the schedule $A B$. The equilibrium occurs at the intersection of $A B$ with the $45^{\circ}$ line $(\widehat{\mu})$. 
An increase in $\lambda$ implies, for $\mu \neq 1$, a more restrictive entry condition for tax evasion, i.e. for a given observed proportion of evaders, there will be less taxpayers willing to evade than before. This lowers the equilibrium number of tax evaders, $m$. Hence an increase in $\lambda$ pivots the schedule $A B$ down through the point $B$. In figure 3 the schedule $A^{\prime} B$ represents the function $m(\mu)$ for a higher $\lambda$. The new equilibrium implies a lower proportion of evaders. So the more important is the reputational loss of being investigated, $\lambda$, the smaller the number of individuals who evade tax.

\section{Effect of an increase in the probability of detection on the number of evaders.}

We want to know how the number of evaders is affected by the probability of detection.

Notice first of all that an increase in $p$ decreases $\bar{\lambda}$ for all values of $\mu$ and so it shifts the schedule $\mathrm{AB}$ down, thus lowering $\widehat{\mu}$, i.e. $\frac{\delta \widehat{\mu}}{\delta p}<0$. Formally we have:

$$
\frac{\delta \widehat{\mu}}{\delta p}=\frac{\frac{\delta m}{\delta p}}{1-\frac{\delta m}{\delta \widehat{\mu}}}
$$

An increase in $p$ causes the marginal individuals to stop evading; this lowers the proportion who evade, which in turns reduces evasion - and so on.

By differentiating (18) with respect to $p$, we get that the impact of a change in the probability of audit is:

$$
\frac{\delta m}{\delta p}=h(\bar{\lambda}) \frac{\delta \bar{\lambda}}{\delta p}+h(\bar{\lambda}) \frac{\delta \bar{\lambda}}{\delta \widehat{\mu}} \frac{\delta \widehat{\mu}}{\delta p}
$$

Notice that the first effect is due to the fact that an increase in the probability of detection makes the entry condition for evasion more restrictive and hence lowers the critical level of importance of the psychic cost $(\bar{\lambda})$ : those on the margin will stop evading. The second argument is the additional effect arising because of taxpayer's interdependencies. As the number of those on the margin stop evading, the magnitude of the psychic cost increases and this discourages even more people to continue evading. We know that $\frac{\delta \bar{\lambda}}{\delta \mu} \geqslant 0$ and that $\frac{\delta \bar{\lambda}}{\delta \widehat{\mu}}=\frac{[t(1-p)-p F] C^{\prime}(1-\widehat{\mu})}{p[C(1-\widehat{\mu})]^{2}}$. Hence the change in $\bar{\lambda}$ due to a change in the equilibrium number of evaders $(\widehat{\mu})$ is positively related to the marginal psychic cost of being audited. The greater $C^{\prime}(\cdot)$, the greater the additional second effect due to social interdependencies, captured in this model by the psychic cost of being investigated.

In figure 4 we decompose the effect of a rise in the audit rate in the two effects described above. The line $A B$ represents the $m$ schedule when the psychic cost attached to being 


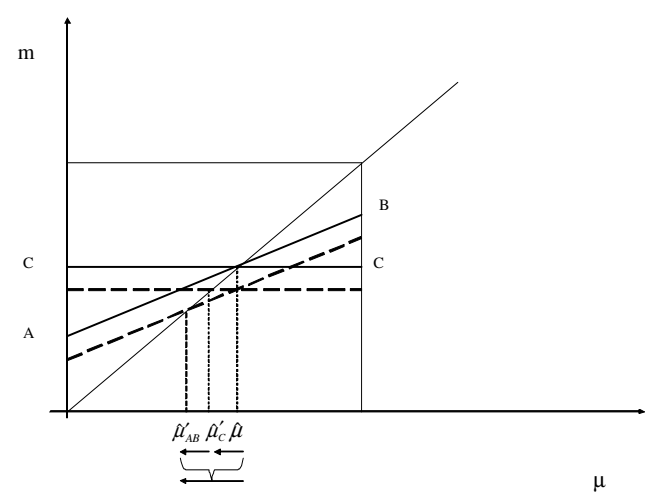

Figure 4: Decomposition of the impact of an increase in the frequency of audit on the number of evaders

audited is an increasing function of the number of honest taxpayers. For simplicity we assume that $m^{\prime}>0$ and $m "=0$. The initial equilibrium is at point $\widehat{\mu}$. The line $C C$ represents the same equilibrium but when the psychic cost of being investigated is constant, so that $\frac{\delta \bar{\lambda}}{\delta \widehat{\mu}}=0$. If the initial equilibrium is $\widehat{\mu}$, a rise in the audit rate will shift both lines parallel downwards. The movement from $\widehat{\mu}$ to $\widehat{\mu}_{C}^{\prime}$ represents the first effect of equation (16), i.e. the decrease in the number of evaders due to an increase in the expected fine, which makes the entry condition for evasion more restrictive. The movement from $\widehat{\mu}_{C}^{\prime}$ to $\widehat{\mu}_{A B}^{\prime}$ represents the second term in the right hand side of equation (16) and it is the extra effect of a rise in the audit rate due to the social norm. Notice that the magnitude of this second effect depends on the slope of the line $A B$, which is determined by $C \prime$, the marginal cost of reputation, i.e. the impact of a change in the number of honest taxpayers in the community on the psychic cost of being investigated.

In conclusion, in the presence of a non-pecuniary cost of being investigated, an increase in the probability of detection will cause the fraction of the population who evades to fall, and this will give an extra reason for people to stop evading over and above the normal deterrence effects. Moreover, the greater the marginal psychic cost, the greater will be the fall in the proportion of evaders. But, in addition, the more weight people give to this effect, $\left(\lambda_{i}\right)$, the more this will cause people on the margin to stop evading ${ }^{14}$. Hence it is possible to explain why the indirect effects of audits may be greater than the

\footnotetext{
${ }^{14}$ We should note that this analysis applies when there is a unique, locally stable equilibrium. In the presence of multiple equilibria we wouldn't be able to use our comparative statics as an increase in the probability of detection would shift the density function down and some initial equilibria might disappear, causing a jump to a different equilibrium.
} 
direct effects: even if taxpayers are not directly subject to an investigation, the greater compliance of those being investigated can trigger a change in their behaviour, through the social psychic cost. Note that these results rely on the assumption that the psychic cost of being audited is not constant, but it increases with the number of other honest taxpayers. Very similar results could be obtained in Myles and Naylor (1996), where individuals get extra utility from conforming with the group of honest taxpayers, which is increasing in the number of other honest taxpayers and gained irrespective of being investigated. Although the authors do not consider this issue, it can be easily shown that an increase in the probability of detection causes the marginal individuals to stop evading; this lowers the proportion who evades, which in turns reduces evasion, as the extra gain from conforming with the honest taxpayers increases - and so on. What matters for the multiplier effect is that the number of other honest taxpayers affects the extra utility of conformity or the psychic cost of being investigated. Note that this assumption allows to explain tax compliance as a social norm: once a critical proportion of honest taxpayers is reached in the community, tax compliance is a self-enforcing behaviour. Hence it's the presence of a social norm that explains the multiplier effect and, consequently, the potential overwhelming role of the indirect effects of investigations.

\section{Conclusion}

In this paper we identify the determinants of the direct and indirect effects in quite a general model and show that the ratio between the two depends on the behavioural elasticity, on how intensively a given group of taxpayers is investigated and on the operational effectiveness of investigations. The intensity and the operational effectiveness of investigations do indeed vary across fiscal areas and also across different groups of taxpayers within the same fiscal area. Hence there is no reason to expect the ratio to be constant across different groups of taxpayers or different fiscalities. A policy implication of this result is that the three elements we identify should be estimated in order to better anticipate the effects of a change in the allocation of investigation resources. However, a reliable estimation of the behavioural elasticity is very difficult if not impossible. One first step in this direction, which we pursue in this paper, is to better understand how different taxpayers' motivations towards compliance may affect the impact of audits. With this aim,

we compare a setting where taxpayers decide whether or not to be honest irrespective of 
the behaviour of other taxpayers with a situation where the taxpayers' decision is interdependent and tax compliance assumes the characteristics of a social norm. Our results suggest that the presence of a social norm has important implications on the impact of an increase in the probability of detection on voluntary compliance. At the aggregate level of the community of taxpayers, we can expect a more important response to a change in the allocation of audit resources than in the absence of a social norm. Essentially, social norms introduce a multiplier effect: generating greater compliance through a deterrent effect causes even more people to become compliant through the social norm. The magnitude of the impact of audits on aggregate behaviour will therefore be higher the greater the importance attached to the social norm. This implies that any policy intervention should be implemented after a good understanding of how interdependencies across taxpayers actually occur. This calls for the identification of a possible reference group, which may differ across different taxpayers and could be based, for example, on occupation, or on neighbourhoods or on the use of the same tax agent. This is a demanding task, but a good point of start could be the analysis of the dynamics of tax declarations by groups of taxpayers, given the detailed individual-level data that the tax authority holds, complemented by the working knowledge and personal experience of tax inspectors.

Another important policy implication is that the announcement of the audit rule or of the investigation results can have a crucial role in re-enforcing the multiplier effect of audits if reputational effects are at work. This raises the question "what kind of announcements could the tax authority make to deter non-compliant behaviour?", which is also of theoretical interest. However, the answer to this question hinges on the type of social interactions that may be at work. As pointed out by Manski (2000), in order to analyse social interactions, it is crucial to distinguish between preference interactions - one person may "imitate" another because the former prefers to act like the latter from the expectation interactions, generated by observational learning - one person may "imitate" another because he/she believes that the other person has superior information. These different explanations of social interactions have different policy implications in that "...Interventions that provide new information may alter the nature of expectations interactions or even cause them to disappear, but should have no effect on preference interactions $^{15}$ ". In the context of tax evasion, expectation interactions could indeed be relevant and, from a theoretical point of view, they could be modelled without invoking

\footnotetext{
${ }^{15}$ See Manski (2000) pp. 131.
} 
any special functional form for the utility function. More specifically, tax evasion is, by its nature, a risky activity. While in the standard theoretical models an individual is assumed to know the probability of being caught, in reality he does not, and he rather makes his compliance decision on the basis of perceptions of such a probability. The amount of evasion undertaken by one's predecessors or peer group may convey information on the uncertainty (risk) of the environment. In particular an individual may observe how many of his peers are evading and are caught and, accordingly, update his prior beliefs on the probability of being caught. In such a context, individuals would care about the relative amount of evasion in their community because they are trying to extract information about the environment, and not because of moral considerations, or altruism. Yet, it would still be the case that tax compliance is self-enforcing behaviour: the greater the number of compliant taxpayers, the more willing an individual is to be compliant. And an increase in the audit rate would still have a multiplier effect. But, as suggested by Manski (2000), the policy implications on the kind of announcements that could be made by the tax authority to deter cheating could be very different. In particular, announcing the results of an audit may have detrimental effects if individuals tend to over-estimate the probability of detection.

Modelling how people form their perceptions about the probability of being investigated would not only help explaining the emergence of tax compliance as a social custom, but it would also allow to distinguish the two components of the individual elasticity of evasion we mentioned above: the sensitivity of evasion behaviour to the perceived frequency of inspections and the sensitivity of the perceived probability of inspection to the actual frequency of inspection.

These are possible extensions of our analysis. 


\section{References}

[1] Akerlof, G. A. (1980) A theory of social custom of which unemployment may be one consequence, Quarterly Journal of Economics, Vol. 95, pp. 749-775

[2] Allingham, M., and Sandmo, A. (1972) Income tax evasion: a theoretical analysis, Journal of Public Economics, Vol. 1, pp. 323-338.

[3] Beron, K.J., H.V. Tauchen, and A.D. Witte (1992) "The Effect of Audits and Socioeconomic Variables on Compliance" in Why People Pay Taxes: Tax Compliance and Enforcement, by Joel Slemrod, ed., The University of Michigan Press, Ann Arbor.

[4] Blumenthal, M., Christian, C., Slemrod, J. (2001) Do normative appeals affect tax compliance? Evidence from a controlled experiment in Minnesota, National Tax Journal, Vol. 54 (1), pp. 125-138.

[5] Bosco, L., Mittone, L. (1997) Tax evasion and moral constraints: some experimental evidence. KYKLOS, Vol. 50, pp. 297-324.

[6] Cowell, F. (1990) "Cheating the government" The MIT Press, Cambridge, MA.

[7] Crane, S., Nourzad, F. (1993) An empirical analysis of factors that distinguish those who evade on their tax return from those who choose not to file a return, Public Finance, Vol. 49, pp. 106-118.

[8] Cremer, H., Marchand, M., Pestieau, P. (1990) Evading, auditing and taxing, Journal of Public Economics, Vol. 43, pp. 67-92.

[9] De Juan, A., Lasheras, M.A., and Mayo, R. (1994) Voluntary Tax Compliant Behavior of Spanish Income Tax Payers, Public Finance, Vol. 49, pp. 90-105.

[10] Dubin, J., M. Graetz and L. Wilde (1990) The Effect of Audit Rates on the Federal Individual Income Tax 1977-1986, National Tax Journal Vol. 43, pp. 395-409.

[11] Dubin, J., (2007) Criminal Investigation Enforcement Activities and Taxpayers Noncompliance, Public Finance Review, Vol. 35 (4), pp. 500-529.

[12] Ellfers, H. (2000) "But taxpayers do cooperate!" in Cooperation in Modern Society: Promoting the Welfare of Communities, States and Organizations, by M. Van Vugt, M. Snyder, T.R. Tyler, A. Biel (eds), London: Routledge, pp. 184-194. 
[13] Erard, B (1992) "The Influence of Tax Audits on Reporting Behavior." in Why People Pay Taxes: Tax Compliance and Enforcement, by Joel Slemrod, ed., The University of Michigan Press, Ann Arbor, pp. 95-114.

[14] Erard, B., Ho, C. (2001) Searching for ghosts: who are the nonfilers and how much tax do they owe?, Journal of Public Economics, Vol. 81, pp. 25-50.

[15] Frey, B. (2003) Deterrence and tax morale in the European Union. European Review, 11(3), 385-406.

[16] Frey, B. and Jegen, R., (2001) Motivation crowding theory, Journal of Economic Surveys, 5, 589-611.

[17] Frey, B., and Torgler, B. (2007) Taxation and Conditional Cooperation, Journal of Comparative Economics, Vol. 35(1), pp. 136-159

[18] Gächter, S. (2006) Conditional cooperation: behavioural regularities from the lab and the field and their policy implications, CeDEx Discussion Paper, No. 2006-03, Nottingham, Centre for Decision Research and Experimental Economics.

[19] Gordon, J. (1989) Individual morality and reputation costs as deterrents to tax evasion, European Economic Review, Vol. 33, pp. 797-805.

[20] Graetz, M., Reinganum, J., Wilde, L. (1986) The tax compliance game: toward an interactive theory of law enforcement, Journal of Law, Economics and Organization, Vol. 2, (1), pp. 1-32.

[21] Grasmick, H., Green, D. (1980) Legal Punishment, Social Disapproval and Internalization as Inhibitors of Illegal Behavior, The Journal of Criminal Law and Criminology, Vol. 71 (3), pp.325-335.

[22] Greenberg, J. (1984) Avoiding tax avoidance: a (repeated) game-theoretic approach, Journal of Economic Theory, Vol. 32, pp.1-13.

[23] Manski, C., (2000) Economic analysis of social interactions, Journal of Economic Perspectives, Vol. 14(3), pp. 115-136.

[24] Myles, G., Naylor, R. (1996) A model of tax evasion with group conformity and social customs, European Journal of Political Economy, Vol. 12, pp. 49-66. 
[25] Orviska, M., Hudson, J. (2002) Tax evasion, civic duty and the law abiding citizen, European Journal of Political Economy, Vol. 19, pp. 83-102.

[26] Plumley A. (1996), The Determinants of Individual Income Tax Compliance. Internal Revenue Service Publication 1916 (Rev. 11-96) Washington, DC

[27] Reinganum, J., Wilde, L. (1985) Income tax compliance in a Principal-Agent framework, Journal of Public Economics, Vol. 26, pp. 1-18.

[28] Reinganum, J., Wilde, L. (1991) Equilibrium enforcement and compliance in the presence of tax practitioners, Journal of Law, Economics and Organization, Vol. 7 (1), pp. 163-181.

[29] Slemrod, J., Blumenthal, M., Christian, C. (2001) Taxpayer response to an increased probability of audit: evidence from a controlled experiment in Minnesota, Journal of Public Economics, Vol. 79, pp. 455-483.

[30] Tauchen, H.V., A.D. Witte, and K.J. Beron (1993) Tax Compliance: An Investigation Using Individual TCMP Data, Journal of Quantitative Criminology, Vol. 9(2), pp. 177-202.

[31] Torgler, B.(2002) Speaking to theorists and searching for facts: tax morale and tax compliance in experiments, Journal of Economic Surveys, Vol. 16(5), pp. 657-683.

[32] Webley, P., Robben, H., and Morris, I. (1988) Social comparison, attitudes and tax evasion in a shop simulation, Social behaviour, Vol. 3, pp. 219-228.

[33] Wrong, P. (1961) The Oversocialized Conception of Men in Modern Sociology, American Sociological Review, Vol. 26, pp. 183-193.

[34] Yitzhaki, S.(1974) A note on Income Tax Evasion: A Theoretical Analysis, Journal of Public Economics, Vol. 3, pp. 201-202. 


\section{Appendix: the targeted auditing.}

In Section 2 we assumed a random audit within a specific group of taxpayers. The tax authority did not have any information of how evasion differs across taxpayers within the same group, so that was not able to distinguish marginal evasion from average evasion withing the same group of taxpayers.

We now suppose that the tax authority has some information about taxpayers that enables it to distinguish the expected amount of evasion that one type of taxpayer might be involved in relative to another.

More precisely, assume that the actual amount of evasion, $e_{j k}$, in which the $\mathrm{j}$-th taxpayer in group $k$ is involved given by:

$$
e_{j k}=\phi_{k}\left(x_{j}, p_{k}\right)+\xi_{k}
$$

where $x_{j}$ is a vector of observable individual characteristics and $\xi_{k}$ is a random variable with zero mean. We assume that the tax authorities have a risk-profiling model that enables to observe for any given taxpayer the expected amount of evasion

$$
\bar{e}_{j k}=\phi_{k}\left(x_{j}, p_{k}\right)
$$

For simplicity, assume that the effectiveness of investigations is independent of taxpayer type and is given once again by the constant $\theta_{k}$.

Since behaviour depends solely on the fraction of people investigated - and not their identity - in order to minimise the tax gap the tax authority will obviously want to target those taxpayers with highest expected evasion.

To understand the implications of this, for expositional simplicity, we assume that $x$ is a scalar and that the distribution of $x$ in the $k$-th group is given by the density function $l_{k}(x)$. We also assume that $\phi(x, p)$ is a strictly increasing function of $x$.

This implies that if a fraction $p_{k}$ of taxpayers in group $k$ are investigated these will be all taxpayers for whom $x \geq \underline{x}_{k}$, where $\underline{x}_{k}$ is defined by

$$
\int_{\underline{x}_{k}}^{\infty} l_{k}(x) d x=p_{k}
$$

For later purposes notice that

$$
-l\left(\underline{x}_{k}\right) \frac{d \underline{x}_{k}}{d p_{k}}=1
$$


As before let $E_{k}\left(p_{k}\right)=\int_{0}^{\infty} \phi_{k}\left(x_{j}, p_{k}\right) l(x) d x$ be the average amount of evasion in group $k$, and let

$$
E_{k}^{t}\left(p_{k}\right)=\frac{\int_{\underline{x}_{k}}^{\infty} \phi_{k}\left(x, p_{k}\right) l_{k}(x) d x}{p_{k}}
$$

be the average amount of evasion amongst the sub-group of group $k$ who are targeted for investigations. Obviously, $E_{k}<E_{k}^{t}$.

Also let $E_{k}^{m}=\phi_{k}\left(\underline{x}_{k}, p_{k}\right)$ be the expected evasion of the marginal taxpayer who is targeted for investigation. Obviously $E_{k}^{m}<E_{k}^{t}$.

Since tax authorities typically only investigate a very small fraction of taxpayers, we would normally expect that $E_{k}<E_{k}^{m}$, and so $E_{k}<E_{k}^{t}$.

Finally let $\varepsilon_{k}=-\frac{d E_{k}}{d p_{k}} \frac{p_{k}}{E_{k}}$ be the sensitivity of taxpayer behaviour to the probability of investigation for the $k$-th group of taxpayers as a whole, and $\varepsilon_{k}^{t}=-\frac{d E_{k}^{t}}{d p_{k}} \frac{p_{k}}{E_{k}^{t}}$ be the sensitivity of the sub-group of taxpayers who are targeted for investigation.

The payment/tax gap of the $k$-th group of taxpayers is

$$
G_{k}=N_{k}\left[E_{k}-\theta_{k} \int_{\underline{x}_{k}}^{\infty} \phi_{k}\left(x, p_{k}\right) l_{k}(x) d x\right]
$$

An alternative way of writing this is

$$
G_{k}=N_{k}\left[E_{k}-\theta_{k} p_{k} E_{k}^{t}\right]
$$

From (38) we get:

$$
M R P G_{k}=-\frac{1}{N_{k}} \frac{d G_{k}}{d p_{k}}=\theta_{k} \phi_{k}\left(\underline{x}_{k}, p_{k}\right)+\frac{E_{k} \varepsilon_{k}}{p_{k}}-\theta_{k} \int_{\underline{x}_{k}}^{\infty}\left[-\frac{\delta \phi_{k}}{\delta p_{k}}\right] l_{k}(x) d x
$$

From (37) it is straightforward to show that

$$
\int_{\underline{x}_{k}}^{\infty}\left[-\frac{\delta \phi_{k}}{\delta p_{k}}\right] l_{k}(x) d x=E_{k}^{t} \varepsilon_{k}^{t}+\left(E_{k}^{m}-E_{k}^{t}\right)
$$

Substitute (41) into (40) and we get:

$$
M R P G_{k}=\theta_{k} E_{k}^{m}+\frac{E_{k} \varepsilon_{k}}{p_{k}}-\theta_{k}\left[E_{k}^{t} \varepsilon_{k}^{t}+\left(E_{k}^{m}-E_{k}^{t}\right)\right]
$$


But notice that we can re-write this as:

$$
M R P G_{k}=\theta_{k} E_{k}^{t}-\theta_{k} E_{k}^{t} \varepsilon_{k}^{t}+\frac{E_{k} \varepsilon_{k}}{p_{k}}
$$

which is the formula one would get from (39).

The formula in (43) is very similar to that in (5).

The question is what we can say from this about the ratio of the indirect to the direct effect of investigation activity. This depends on what one means by the direct and indirect effect - the average or marginal effect of the tax authority activity.

If we defined the direct effect as $\theta_{k} E_{k}^{t}$ - i.e. the average yield form an investigation then, from (43), the formula for the ratio of the indirect effect to the direct effect would be:

$$
R_{3 k}=\varepsilon_{k}\left[\frac{E_{k}}{E_{k}^{t}} \frac{1}{p_{k} \theta_{k}}-\frac{\varepsilon_{k}^{t}}{\varepsilon_{k}}\right]
$$

If the tax authority were unable to target investigation resources then we would have $E_{k}=E_{k}^{t} ; \varepsilon_{k}=\varepsilon_{k}^{t}$ and (44) would collapse to (8).

If the tax authority were able to target,but there were no reason to think that the behavioural response of targeted taxpayers was significantly different from non-targeted taxpayers, then we would have $E_{k}<E_{k}^{t} ; \varepsilon_{k} \approx \varepsilon_{k}^{t}$ and so we would have

$$
R_{3 k} \approx \varepsilon_{k}\left[\frac{E_{k}}{E_{k}^{t}} \frac{1}{p_{k} \theta_{k}}-\frac{\varepsilon_{k}^{t}}{\varepsilon_{k}}\right]<\varepsilon_{k}\left[\frac{1}{p_{k} \theta_{k}}-1\right]
$$

and so, as we might expect, targeting gives a lower ratio of the indirect to the direct effect.

However this approach would be very odd since the direct doesn't reflect the fact that the tax authority is targeting resources and so, if given extra resources, would deploy those on the marginal taxpayer. So if we define the direct effect as $\theta_{k} E_{k}^{m}$ - i.e. the marginal yield per investigation - then, from (42), the ratio of the indirect effect to the direct effect is:

$$
R_{3 k}=\varepsilon_{k} \frac{E_{k}^{t}}{E_{k}^{m}}\left[\frac{E_{k}}{E_{k}^{t}} \frac{1}{p_{k} \theta_{k}}-\frac{\varepsilon_{k}^{t}}{\varepsilon_{k}}\right]+\left[\frac{E_{k}^{t}}{E_{k}^{m}}-1\right]
$$

If we compare (46) with (44) then we see that the expression on the RHS of (46) is larger than the expression on RHS of (44) - which is not surprising since the MRPG is the same and, in (46) we are using as denominator the marginal direct effect which is smaller than the average, which is denominator in (44). This shows up in two ways. First of all we 
have to multiply (44) by $\frac{E_{k}^{t}}{E_{k}^{m}}>1$ - which is a re-scaling effect to reflect the different denominators - but then we have to add $\left(\frac{E_{k}^{t}}{E_{k}^{m}}-1\right)>0$.

If the coverage rate is very low then we would expect the marginal and average values to be very similar, so, the values we get in (44) and (46) are likely to be very similar.

Once again, if the tax authority were unable to target investigation resources then we would have $E_{k}=E_{k}^{t} ; \varepsilon_{k}=\varepsilon_{k}^{t}$ and (46) would collapse to (8).

If the tax authority were able to target, but there were no reason to think that the behavioural response of targeted taxpayers was significantly different from non-targeted taxpayers, then we would have $E_{k}<E_{k}^{m}<E_{k}^{t} ; \varepsilon_{k} \approx \varepsilon_{k}^{t}$ and so we would have

$$
R_{3 k} \approx \varepsilon_{k} \frac{E_{k}^{t}}{E_{k}^{m}}\left[\frac{E_{k}}{E_{k}^{t}} \frac{1}{p_{k} \theta_{k}}-1\right]+\left[\frac{E_{k}^{t}}{E_{k}^{m}}-1\right]
$$

What this suggests is that in many circumstances the ratio of the indirect effect to the direct effect could be well approximated by

$$
R_{3 k} \approx \varepsilon_{k}\left[\frac{E_{k}}{E_{k}^{t}} \frac{1}{p_{k} \theta_{k}}-1\right]
$$

which is just a mild adjustment to the original formula in (8). 